\title{
Modal properties variation and collapse assessment of masonry arch bridges under scour action
}

\author{
F. Scozzese ${ }^{1}$, L. Ragni ${ }^{1}$, E. Tubaldi ${ }^{2}$, F. Gara ${ }^{1}$ \\ ${ }^{1}$ Department of Construction, Civil Engineering and Architecture, Università Politecnica delle \\ Marche, Via Brecce Bianche, Ancona (AN), Italy. \\ ${ }^{2}$ Department of Civil and Environmental Engineering, University of Strathclyde, 75 Montrose \\ Street, G1 $1 X Q$ Glasgow, United Kingdom
}

\begin{abstract}
This paper investigates the problem of flood-induced scour on masonry arch bridges through the analysis of a real case study, Rubbianello Bridge. This is a multi-span masonry arch bridge located in Central Italy, which suffered the collapse of two of the seven spans due to foundation scour during a severe flood in December 2013. The study has a twofold aim: to evaluate with a numerical model the level of scour which led to the bridge failure in 2013 and the corresponding collapse mechanism, and to assess the sensitivity of the bridge's modal properties (vibration frequencies and mode shapes) to different levels of scour. An accurate nonlinear three-dimensional model of the bridge is developed, whose elastic properties are calibrated to match the results of dynamic identification tests performed via Operational Modal Analysis (OMA) on the remaining portion of the bridge. A numerical simulation of the effects of the scour hole progression is also performed on the full bridge, according to recently proposed techniques. The study results provide useful insights on both the cause of collapse of the bridge and the suitability of OMA for bridge scour monitoring.
\end{abstract}

Keywords: masonry, bridges, scour, operational modal analysis, Abaqus FEM

\section{INTRODUCTION}

Flood-induced scour is the erosive effect and removal of streambed or bank material from bridge foundations located within the riverbed. This action is among the most common causes of bridge failure worldwide [1-3], leading to notable direct and indirect losses. A notable example of bridge 
failure due to scour is the Hintze Ribeiro Bridge in Portugal, a steel concrete composite bridge collapsed the night of March 42001 after two decades of uncontrolled sand extraction [4], causing more than 50 victims. The railway bridge of the Dublin-Belfast line (concrete and masonry structure), has undergone the collapse of a span due to the pier's settlement induced by the scour in September 2009, causing the line to be closed for seven months and a repair bill in the region of $€ 4$ million [5]; Further examples of scour-induced collapses are comprehensively discussed in [6].

Masonry arch bridges are particularly vulnerable to the problem of scour and scour-induced settlements, due to their high stiffness and the fact that they are often built on shallow footings resting on the riverbed. Given the high number of masonry-arch bridges in Europe and worldwide [7] and their socio-economic and cultural heritage value, the accurate prediction of their capacity against scour is of paramount importance. The problem has been addressed to date only by few numerical studies, employing soil-foundation-structure interaction models with different level of complexity $[3,8]$. These studies have shed light on the importance of properly accounting for the scour hole shape in assessing the bridge capacity against scour and the collapse mechanism. The use of threedimensional numerical models is also unavoidable to correctly describe the complex behaviour of these structural systems. In the recent years, advanced models have been proposed that also permit to describe with accuracy the evolution of the cracking mechanism in the masonry components (see e.g. $[3,9,10])$. These are useful for tracking the bridge behaviour under levels of scour that are not so severe to induce collapse, but that may lead to bridge closure for repair actions. On the same time, studies have been carried out to investigate the possibility of detecting scour by tracking the changes of the dynamic properties of the bridge-foundation-soil system (see e.g. the studies of $[11,12]$ in the context of masonry arch bridges, or the ones of $[13,14]$ for steel and reinforced concrete bridges). The present paper aims to further investigate the problem of flood-induced scour on masonry bridges, by examining the case of Rubbianello Bridge. This is a multi-span masonry arch bridge located in Central Italy, which suffered the collapse of two of the seven spans due to foundation scour during a 
very severe flood in December 2013, and of two more spans in 2016, again during another major flood event.

Two objectives are sought in this study: the first one is to simulate numerically the collapse mechanism of the bridge and to assess the level of scour which led the bridge to fail in 2013; the second one is to analyse the sensitivity of the bridge modal properties (vibration frequencies and mode shapes) to different levels of scour, in order to evaluate the suitability of Operational Modal Analysis (OMA) $[15,16]$ for scour detection purposes.

In 2018, an experimental campaign was carried out to characterize the dynamic properties of the remaining spans of the bridge in terms of vibration frequencies and mode shapes. For this purpose, ambient vibration tests were performed, complementing the information already available from material characterization tests. The results from these tests are very useful for the development of an accurate and reliable numerical model of the bridge.

In the first part of the paper, a finite element model of the remaining bridge portion is developed and calibrated using measured dynamic test data. Subsequently, an advanced nonlinear model of the full bridge is built to simulate the progression of the scour at the base of the pier collapsed in 2013, thus providing insights about the collapse mechanism of the bridge under the first major flood. In the final part of the paper, the changes of frequency and shape of the most sensible transverse mode of vibration are analysed under different levels of scour. The results of this investigation allow the evaluation of the suitability of the OMA-based identification technique for scour monitoring and early warning purposes.

\section{CASE STUDY: RUBBIANELLO BRIDGE}

Built in 1906, the investigated masonry arch bridge crosses the Aso river, located in Rubbianello municipality, a small town in Central Italy. This bridge originally consisted of seven spans, six masonry piers, a granular mixture fill and segmental brick vaults. A very severe flood in December 2013 caused the collapse of two of the seven spans (Figure 1), due to the effect of scour at the base 
of the sixth pier foundation, i.e., the one located adjacent to the right abutment looking at the bridge from the up-stream side. The collapse mechanism of the bridge was characterized by a rotational movement of the pier towards the upstream side, a very recurrent mechanism in bridges subjected to scour [3]. This is due to the fact that the scour hole often presents a non-symmetric shape, with the up-stream side steeper than the down-stream one [1].

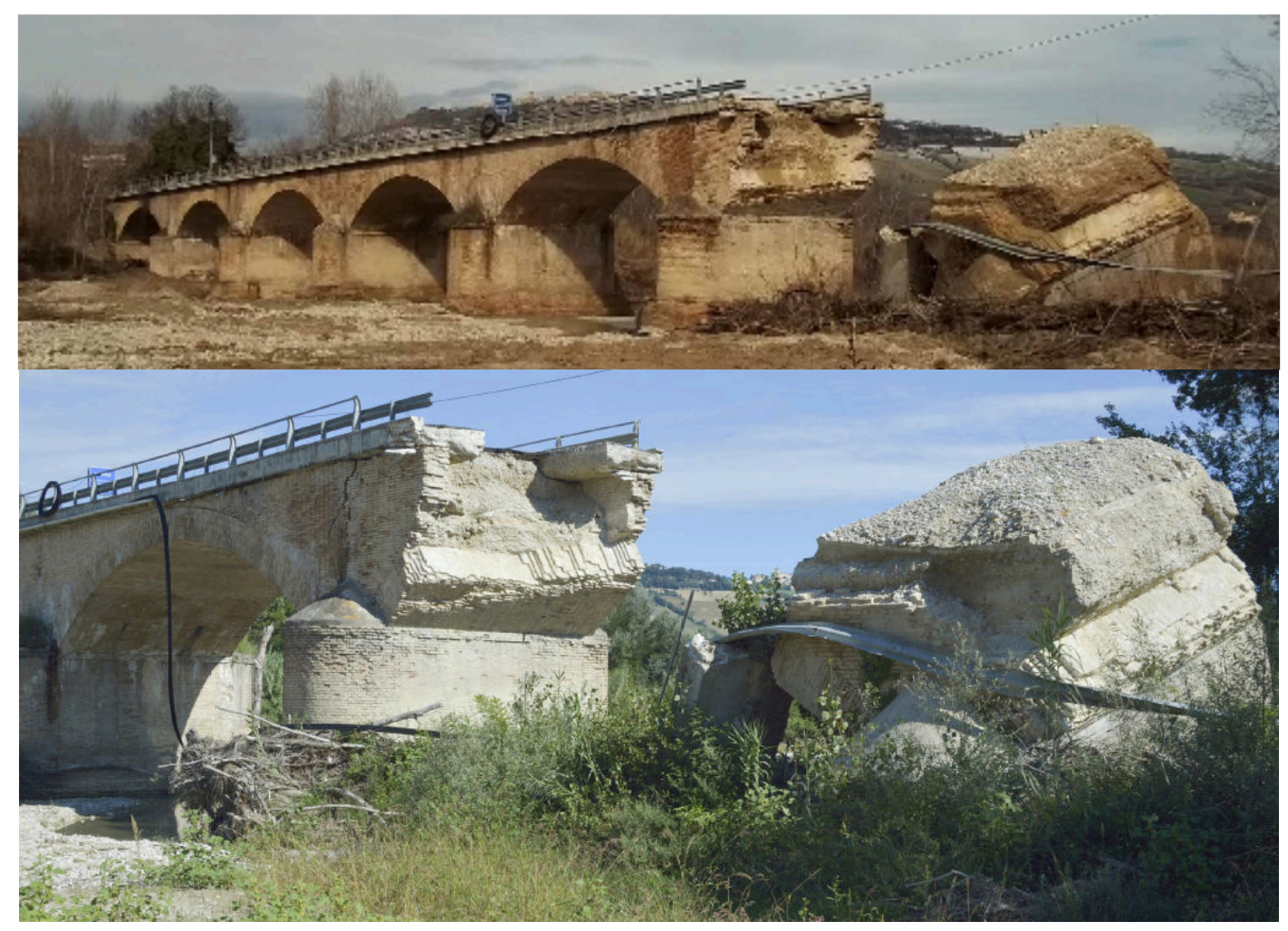

Figure 1. Global view of the bridge after the pier collapse during the 2013 flood and detail of the scour-induced down-stream rotation of the pier.

The bridge experienced further collapse of two more spans following the flood of March 2016. Afterwards, the seismic events of August and October 2016 and the heavy rains and floods recorded until February 2017 led to the actual state of the bridge, which consists of 3 piers and 3 bays, for a total length halved with respect to the beginning (Figure 2).

It is worth noting that the Aso river (as well as several other rivers) can be classified as a meandering river, in which sediments are eroded along the outer bank and deposited on the other (inner) bank further downstream. Such rivers do not proceed straight within the riverbed but develop a channel that winds its way across the foodplants, showing sudden changes of the path. 
According to the hydraulic studies performed in 2013, the year the first collapse occurred, the meanders developed by the Aso river were such that the main channel was located exactly underneath the sixth pier. Such meandering configuration of the river is also testified by the photograph in Figure 3 , showing the path of the riverbed (highlighted by a blue line) at the end of 2015, which is a few months before the second collapse occurred, involving the two piers located in proximity of the main channel.

During the flood event, the free water level rises and the hydraulic section is higher than the one of the main channel (meander). However, the velocities across the river section are not uniform, but they are generally higher in the mainstream (i.e., where the water is deeper). Such hydraulic condition and the already triggered excavation underneath the piers directly involved by the meanders are responsible for a localised scour action.

The aspects discussed above motivated the choice of considering the scour acting at the base of pier n. 6 only, and the assumption that the other piers did not experience this phenomenon in a significant way.

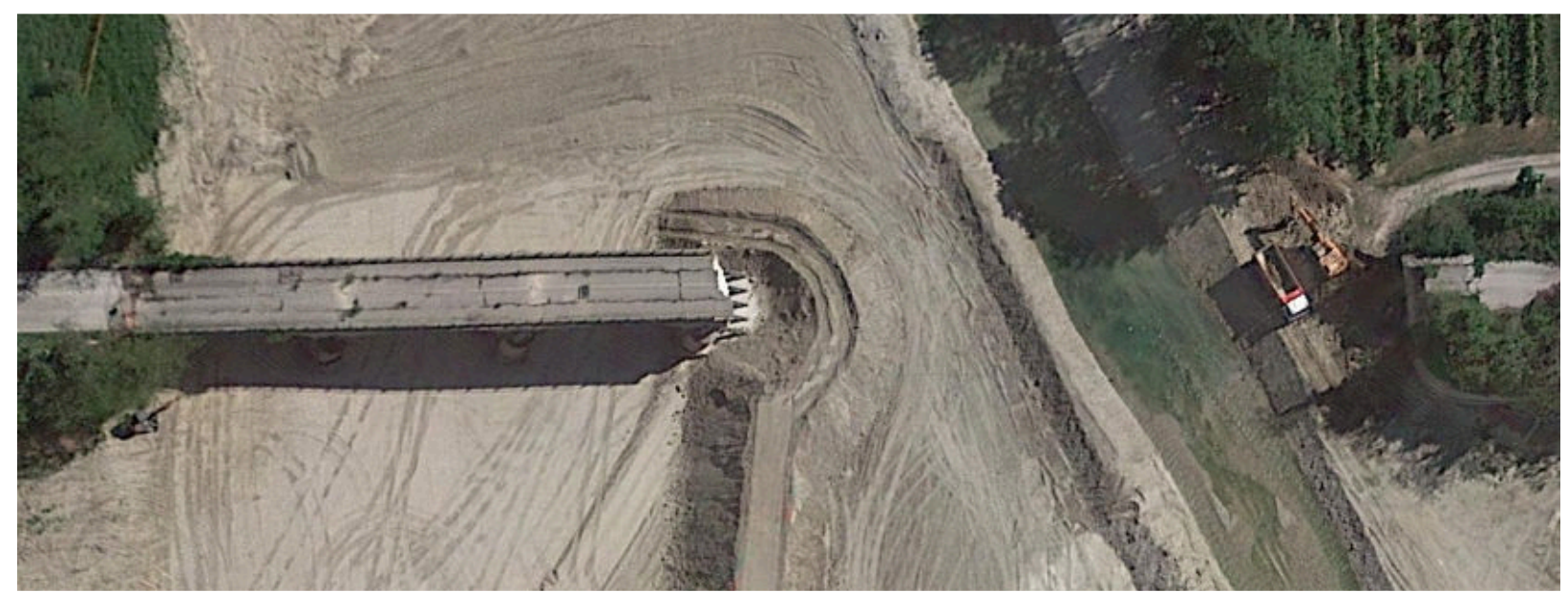

(a) 


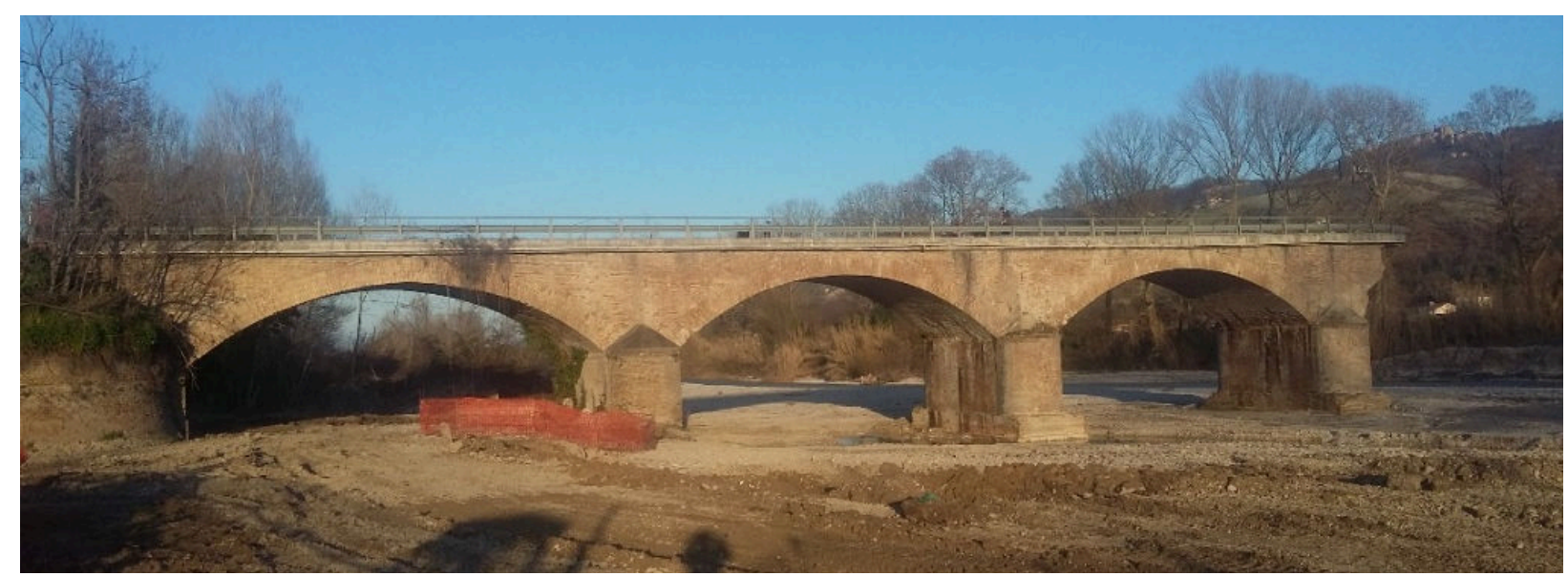

(b)

Figure 2. Current state of the bridge (year 2019), with 3 piers and 3 spans remaining: (a) top-view and (b) lateral view.

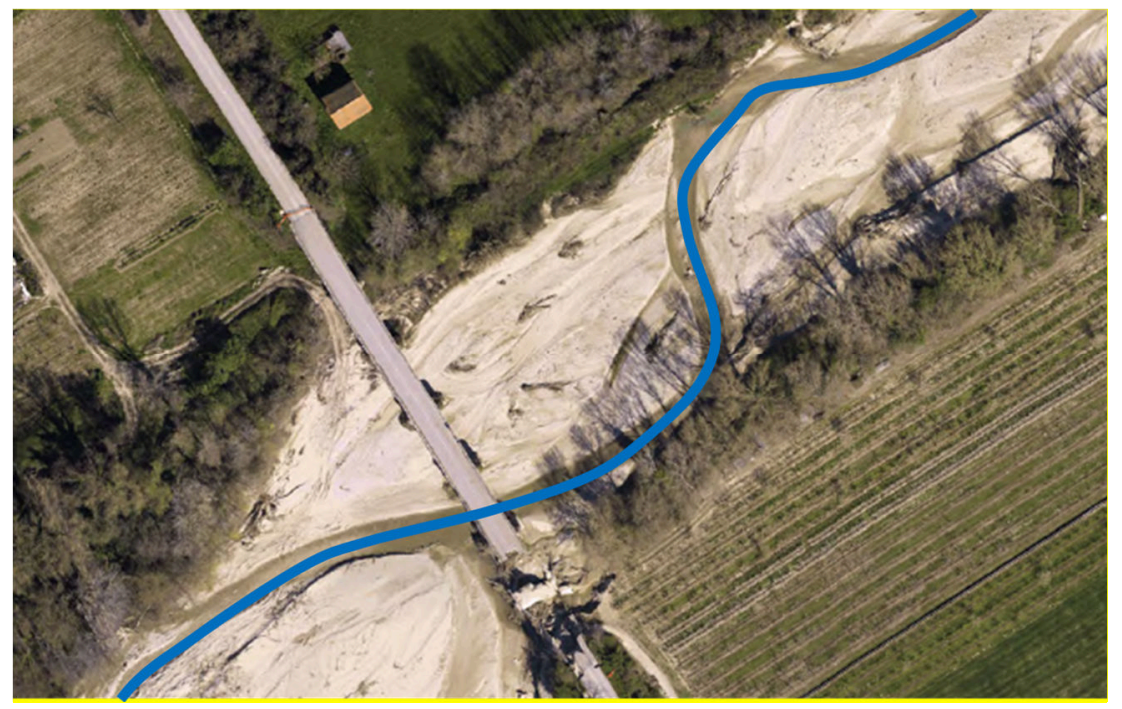

Figure 3. Path of the meandering Aso river in 2015 (a few months before the collapse of piers n. 4 and n. 5).

\subsection{Geometry}

The bridge original length was $131.20 \mathrm{~m}$, with spans of $16.00 \mathrm{~m}$ length. The piers are identical, with a plan size of $9.5 \mathrm{~m} \times 3.2 \mathrm{~m}$, excluding the extreme circular parts with a radius of $2.0 \mathrm{~m}$ along the transverse direction ( $\mathrm{Y}$ direction). The arches have thickness of $0.95 \mathrm{~m}$ and a radius of $11.58 \mathrm{~m}$. Spandrel walls have thickness of $0.65 \mathrm{~m}$. The pier foundations have a rectangular plan shape of 11.00 $\mathrm{m} \times 3.90 \mathrm{~m}$ and their height is $4.15 \mathrm{~m}$. More details about the bridge geometry are given in Figure 4, showing a lateral longitudinal scheme of the bridge (Figure 4a) and two sections (Figure 4b), one transversal and one longitudinal. 

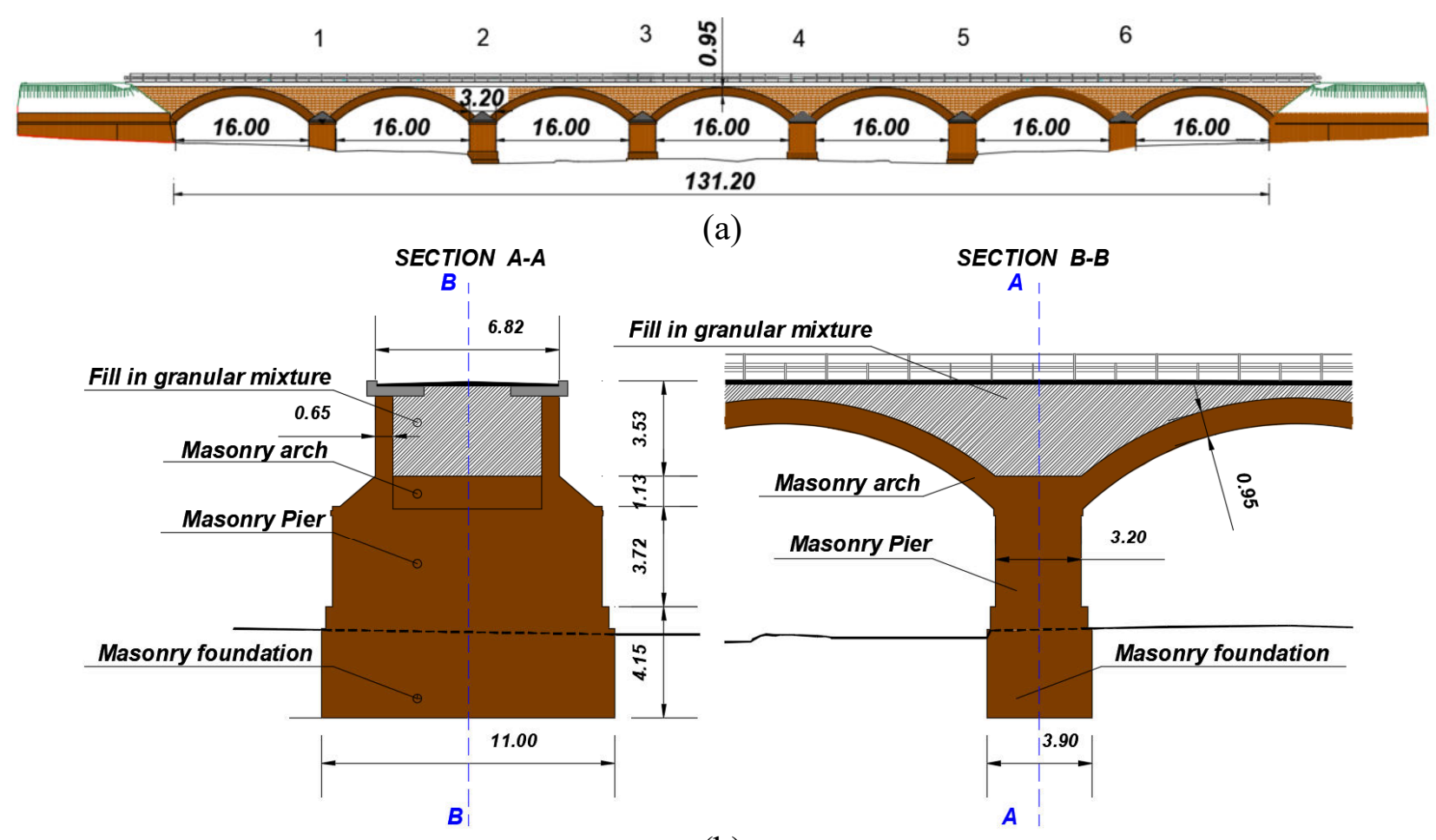

(b)

Figure 4. Geometrical details of the Rubbianello bridge.

\subsection{Materials}

The materials mechanical properties are based on both in-situ and laboratory characterization tests, where available, and on literature values otherwise. The backfill and abutment properties have been set based on reference literature values $[3,9,10]$. Compression tests carried out on 3 samples of size $29.5 \times 29.5 \times 58.0 \mathrm{~m}^{3}$ taken from the bridge have allowed to characterize the first cracking and ultimate stress values of the masonry components. The Young modulus of the piers is the average of the values obtained by two double flat-jack tests, performed during an experimental campaign in 2015 by a third-party company. The rest of the materials' elastic properties have been calibrated based on the experimental data provided by the dynamic identification tests via operation modal analysis (see Section 3.2).

Table 1 provides a summary of the main mechanical properties of the bridge materials, in terms of density $\rho$, Young's modulus $E$, yield stress in compression $f_{y, c}$ (or cohesion $c$ for what concerns the backfill) and peak tensile stress $f_{y, t}$. 
Table 1. Material properties.

\begin{tabular}{ccccc}
\hline $\begin{array}{c}\text { Material } \\
{[-]}\end{array}$ & $\begin{array}{c}\rho \\
{\left[\mathrm{t} / \mathrm{m}^{3}\right]}\end{array}$ & $\begin{array}{c}E \\
{\left[\mathrm{kN} / \mathrm{m}^{2}\right]}\end{array}$ & $\begin{array}{c}c-f_{y, c} \\
{\left[\mathrm{kNN} / \mathrm{m}^{2}\right]}\end{array}$ & $\begin{array}{c}f_{y, t} \\
{\left[\mathrm{kN} / \mathrm{m}^{2}\right]}\end{array}$ \\
\hline Masonry (Arches \& Spandrels) & 1.80 & 3100000 & 2000 & 150 \\
\hline Masonry (Piers) & 1.75 & 2900000 & 2000 & 150 \\
\hline Backfill & 1.70 & 250000 & 10 & 0 \\
\hline Abutment & 1.90 & 300000 & - & - \\
\hline
\end{tabular}

\subsection{Riverbed}

Except for the first meter below the surface, with poor mechanical properties and neglected in the model, the riverbed is mainly composed by highly dense gravel and sands (alluvial deposit extending $27 \mathrm{~m}$ below the surface). Geophysical and mechanical soil characterization was achieved through a set of both in-situ tests (i.e., downhole seismic testing) and laboratory tests carried out on soil samples, performed in 2017 by a third-party company for investigating the state of the bridge and evaluate possible retrofit interventions. Table 2 summarises the mechanical and geophysical properties evaluated based on these tests: friction angle $\phi$, Young's modulus $E$, Poisson's ratio $v$, shear modulus $G$, soil density $\rho$, and average shear waves velocity $v_{s}$.

Table 2. Soil parameters.

\begin{tabular}{cccccc}
\hline $\begin{array}{c}\phi \\
{\left[{ }^{\circ}\right]}\end{array}$ & $\begin{array}{c}E \\
{\left[\mathrm{kN} / \mathrm{m}^{2}\right]}\end{array}$ & $\begin{array}{c}v \\
{[-]}\end{array}$ & $\begin{array}{c}G \\
{\left[\mathrm{kN} / \mathrm{m}^{2}\right]}\end{array}$ & $\begin{array}{c}\rho \\
{\left[\mathrm{t} / \mathrm{m}^{3}\right]}\end{array}$ & $\begin{array}{c}v_{s} \\
{[\mathrm{~m} / \mathrm{s}]}\end{array}$ \\
\hline 38 & 1065000 & 0.45 & 370000 & 2.0 & 430 \\
\hline
\end{tabular}

\section{ABAQUS MODEL AND CALIBRATION}

A 3D model is developed in ABAQUS 2017 (Figure 5), by accounting for both geometrical and mechanical nonlinearities. Details about the modelling issues are given in Subsection 3.1, while the model elastic parameters calibration is described in Subsection 3.2, where the numerical modal results are compared to those provided by the experimental tests based on OMA. 


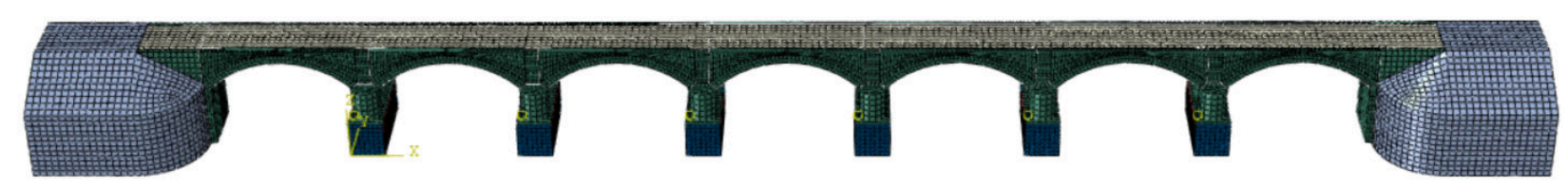

(a)

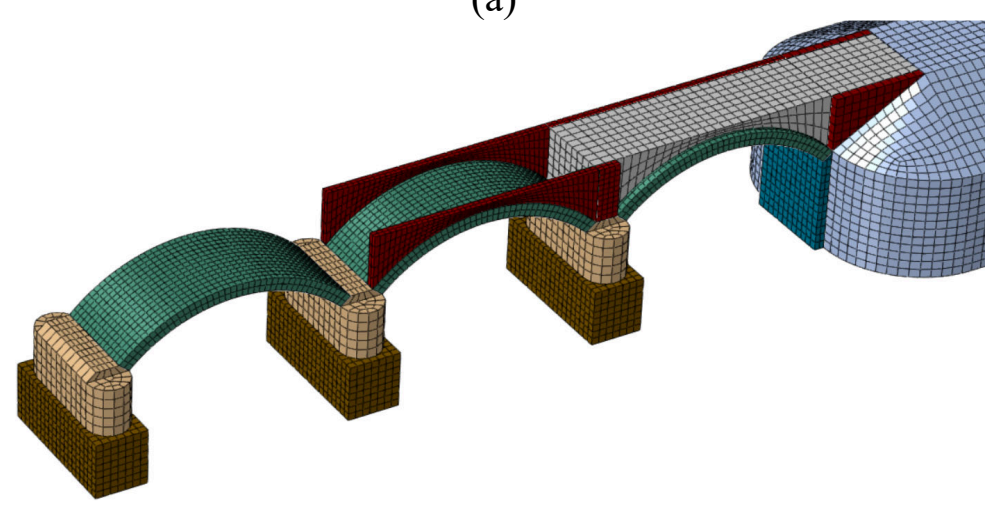

(b)

Figure 5. Finite element model: (a) whole bridge and (b) half bridge with material parts highlighted.

\subsection{Bridge finite element model}

\subsubsection{Type of elements and mesh}

The bridge model is built by using continuum (solid) elements. Single 3D deformable parts are first generated and successively assembled to form the final geometry of the structural system at hand. The domain is discretized using linear hexahedral 8-nodes elements of type C3D8R, with 6 degrees of freedom per node. Parts with complex shapes are previously cut into simpler and more regular shapes in order to ease the automatic mesh procedure.

The number of elements used (i.e., the mesh discretisation) varies from part to part, based on the following two main criteria: 1) attainment of a good trade-off between results' accuracy and computational effort; 2) a coarser mesh is attributed to master parts in defining contact pairs interaction, in order to avoid penetration at the interface. The element dimension varies in the range between $0.35 \mathrm{~m}$ and $0.75 \mathrm{~m}$. 


\subsubsection{Materials constitutive laws}

Different constitutive properties are used for the various constituent materials of the model. The behaviour of the masonry components in the linear elastic field is described by assigning the properties summarised in Table 1. The non-linear behaviour is described through the Concrete Damage Plasticity (CDP) model. This model, available in Abaqus Standard [17], is characterized by a non-associated flow rule, and is suitable for simulating the nonlinear, softening behaviour of quasibrittle materials. The stress-strain under uniaxial tension is linear elastic until the peak cracking stress is attained, followed by a softening branch [10] due to propagation of micro-cracking within the material. The stress-strain under uniaxial compression is linear elastic until the yield stress is attained, followed by a nonlinear strain hardening branch until the ultimate compressive stress which is lastly followed by softening. The adopted masonry constitutive relationship in terms of stress-plastic strain in compression and tension are illustrated in Figure 6.

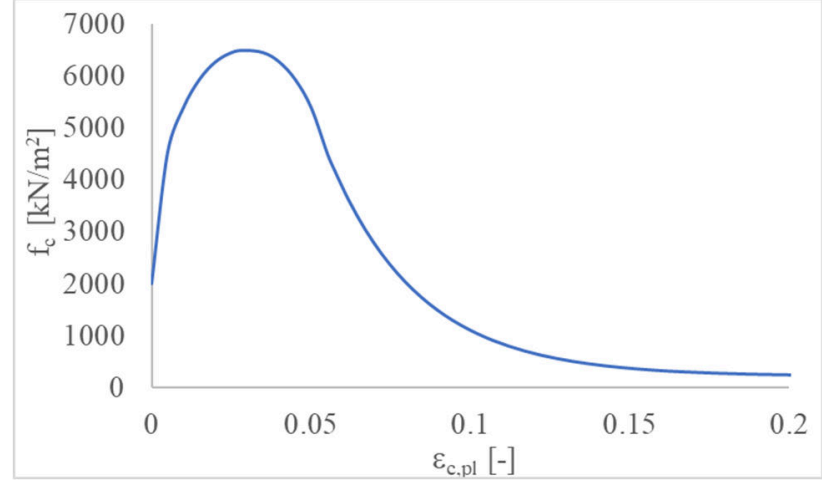

(a)

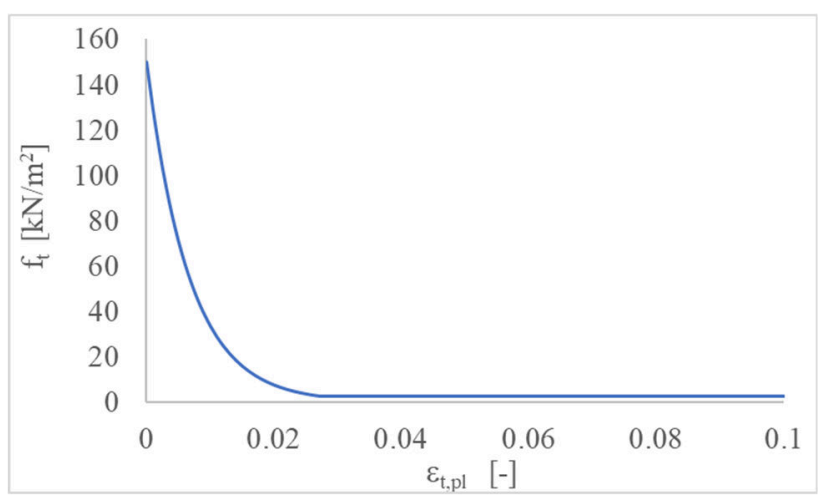

(b)

Figure 6. Stress-plastic strain relationship for masonry (a) in compression and (b) in tension.

The parameters governing the CDP model are as follows [17]: dilation angle $\left(31^{\circ}\right)$; flow potential eccentricity (0.1), a small positive number defining the rate at which the hyperbolic flow potential approaches its asymptote; $f_{b 0} / f_{c 0}(1.16)$, the ratio of initial equibiaxial compressive yield stress to initial uniaxial compressive yield stress; $K(0.67)$, a parameter defining the ratio of the second stress invariant on the tensile meridian to that on the compressive meridian at initial yield ( $K$ modifies the standard Drucker-Prager strength domain). 
For the fill material, a linear elastic model is employed, together with a Mohr-Coulomb failure criterion, characterized by a friction angle of $55^{\circ}$ and a cohesion of $10 \mathrm{kN} / \mathrm{m}^{2}$.

\subsubsection{Nonlinear material interfaces}

The interaction between the different bridge components is simulated by means of nonlinear frictional/cohesive interfaces $[3,9]$ (see Figure 7 for a schematic summary of the modelled interfaces and relevant typologies). More specifically, a frictional interface is used to describe the interaction between the fill and the other bridge components along the tangential direction. The tangential behaviour is characterised by a friction coefficient of 0.60 , while a "hard-contact" behaviour is assumed along the normal direction, allowing separation but preventing penetration between the parts in contact. Similarly, cohesive interactions are used at the spandrel-to-arch, spandrel-to-pier and archto-pier interfaces. In this case, the interaction properties simulate the behaviour of mortar joints between the parts. Besides the tangential and normal behaviour, modelled as for the frictional interface (with a friction coefficient equal to 1.0), a cohesive behaviour is also introduced by means of the following parameters: normal stiffness $K_{n}=0.4 \cdot 10^{9} \mathrm{kN} / \mathrm{m}^{3}$, and tangential stiffness $K_{t}=$ $0.167 \cdot 10^{9} \mathrm{kN} / \mathrm{m}^{3}$. Moreover, a damage criterion is introduced, whose initiation is governed by the attainment of the maximum nominal stress values along the normal and tangential directions, equal to $f_{n, \max }=150 \mathrm{kN} / \mathrm{m}^{2}$ (Table 1) and $f_{t, \max }=1.4 \cdot f_{n, \max }=220 \mathrm{kN} / \mathrm{m}^{2}$, respectively. The damage evolution is described by the Benzeggagh-Kenane mixed mode fracture criterion, with a power-law exponent of 2.2, and the values of normal and shear fracture energies are assumed equal to $G_{f, n}=0.05 \mathrm{kN} / \mathrm{m}$ and $G_{f, s}=0.10 \mathrm{kN} / \mathrm{m}$, respectively. To improve convergence, a damage stabilization criterion is also used, by defining a viscous coefficient of $10^{-5} \mathrm{kNs} / \mathrm{m}$.

The values of the parameters describing the interfaces have not been evaluated experimentally, but they are consistent with those reported in other studies in the literature on masonry arch bridges $[3,10]$. 


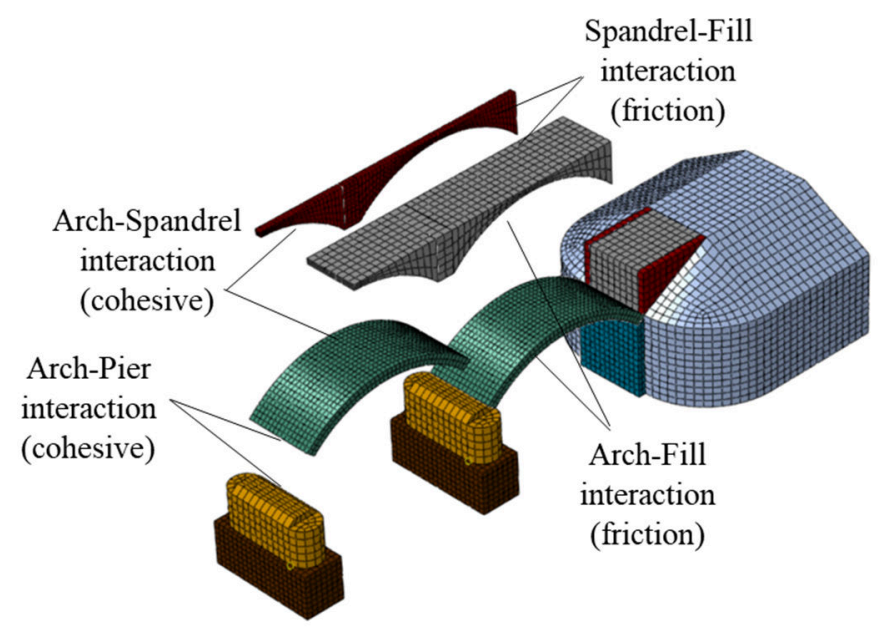

Figure 7. FE model with highlighted materials interface types.

\subsubsection{Riverbed's soil modelling}

Similarly to Tubaldi et al. [3], a Winkler modelling approach is employed to describe the soilfoundation interaction, using zero-thickness cohesive elements surrounding the foundation. These cohesive elements have a zero tensile resistance and a linear elastic behaviour in compression. The relationship between the soil pressure and the corresponding settlement is described by the coefficient of reaction $k$, whose value depends on the footing size and can be estimated on the basis of plate load tests or through analytical expressions. Different impedances formulations are available in the scientific literature [18,19]; in this study, the expression developed by Gazetas [19] are used, furnishing the impedances $k_{x}, k_{y}, k_{z}$ (unit $\mathrm{kN} / \mathrm{m}$ ) along the three directions $x, y, z$ of a rigid embedded foundation as a function of its geometry and of the soil shear modulus $G$.

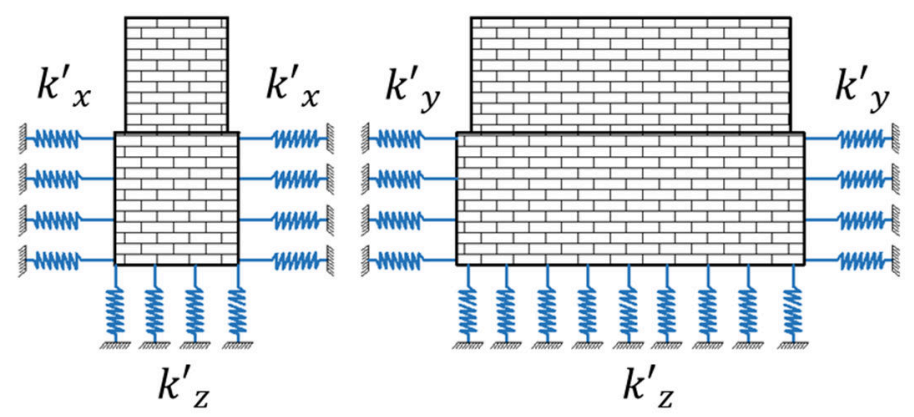

Figure 8. Impedances along the $x, y, z$ directions 
The corresponding values of the subgrade reactions $k_{x}^{\prime}, k^{\prime}{ }_{y}, k_{z}^{\prime}$ can be evaluated by uniformly distributing the impedances along the foundation surfaces $A_{x}, A_{y}, A_{z}$ as follows:

$$
k_{x}^{\prime}=\frac{k_{x}}{A_{x}} \quad k^{\prime}{ }_{y}=\frac{k_{y}}{A_{y}} \quad k_{z}^{\prime}=\frac{k_{z}}{A_{z}}
$$

The distributed impedance values for the present case study are summarized in Table 3.

Table 3. Impedances per unit area.

\begin{tabular}{ccc}
\hline $\boldsymbol{k}^{\prime}{ }_{\boldsymbol{x}}$ & $\boldsymbol{k}^{\prime}{ }_{\boldsymbol{y}}$ & $\boldsymbol{k}_{\boldsymbol{z}}^{\prime}$ \\
{$\left[\mathrm{kN} / \mathrm{m}^{3}\right]$} & {$\left[\mathrm{kN} / \mathrm{m}^{3}\right]$} & {$\left[\mathrm{kN} / \mathrm{m}^{3}\right]$} \\
\hline 220000 & 420000 & 940000 \\
\hline
\end{tabular}

\subsubsection{Scour progression modelling}

Scour is a natural phenomenon caused by erosion or removal of streambed or bank material from bridge foundations due to flowing water $[1-3,20]$. In this study, the scour hole shape is described by a constant inverted pyramidal form, as in [3] (Figure 9). The vertex of the pyramid is assumed along a vertical line passing through the centre of the upstream face of the pier, the upstream slope of the hole is taken equal to friction angle at rest of the soil, $\phi$, whereas the downstream slope is approximately half that value, consistently with [1]. It is also assumed that the scour hole slope along the direction perpendicular to the flow is equal to $5 / 6 \cdot \phi$. Being the shape of the scour hole fixed, the hole geometry is completely defined by the maximum scour depth $y_{s}$, identifying the scour hole vertex, and by the value of the friction angle of the soil, assumed equal to $38^{\circ}$ for the present case study.

The scour progression is simulated numerically by performing a time-history analysis. At each time step, the level of the maximum scour depth is increased and the depth of the centroid of each cohesive element representing the foundation-soil interaction is compared with the depth of scour at the same location. If the element centroid is within the scour hole, then the element is deactivated. In this study, the simulation of the deepening of the scour hole is described by considering 8 discrete steps. Figure 9 illustrates the development of the scour hole at three different stages: at the early stages of the scour 
developments, where the excavation involves only the vertical up-stream side of the foundation; a medium-advanced stage, where the soil under the pier has been partially removed; the last stage of the scour progression, where the pier is completely detached from the surrounding soil.
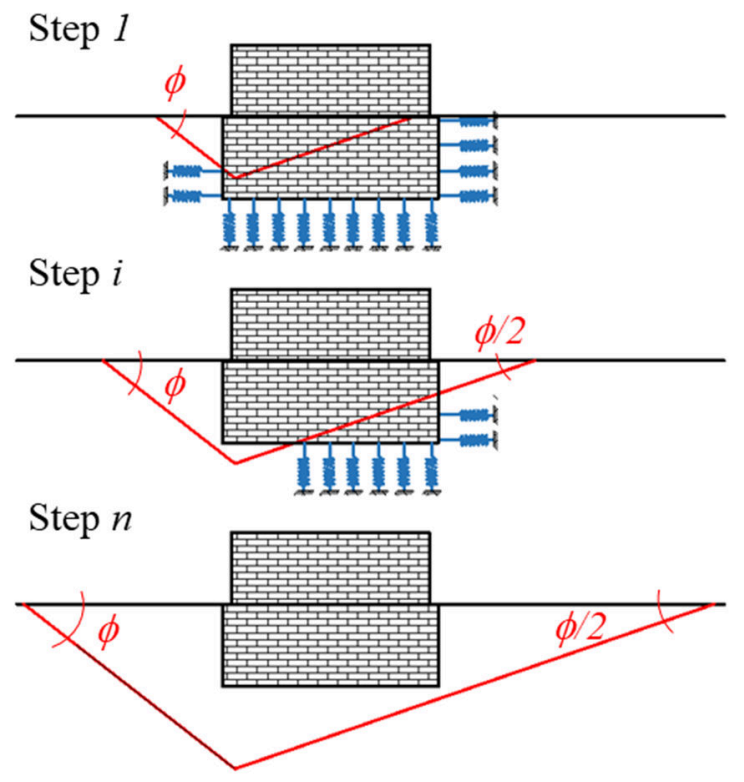

Figure 9. Scheme of scour progression modelling.

Step 0 corresponds to the starting condition, with gravity loads acting on the bridge (self-weight loads plus a uniform pressure of $6.6 \mathrm{kN} / \mathrm{m}^{2}$ simulating the road pavement loads) and no scour. From Step 1 to Step 7, the scour development is simulated by considering increments of $y_{s}$ equal to $1.0 \mathrm{~m}$ per step, for a total maximum scour depth of $7.0 \mathrm{~m}$ attained at Step 7, corresponding to an excavation of $3.0 \mathrm{~m}$ under the base of the pier's foundation (whose height is $4.15 \mathrm{~m}$ ). For sake of clarity, highlighted in Figure 10 are the cohesive elements (modelling the impedances) that are deactivated at four consecutive steps of analysis: Step 2, with $y_{s}=2.0 \mathrm{~m}$ (Figure 10a); Step 4, with $y_{s}=4.0 \mathrm{~m}$ (Figure 10b); Step 5, with $y_{s}=5.0 \mathrm{~m}$ (Figure 10c); Step 6, with $y_{s}=6.0 \mathrm{~m}$ (Figure 10d).

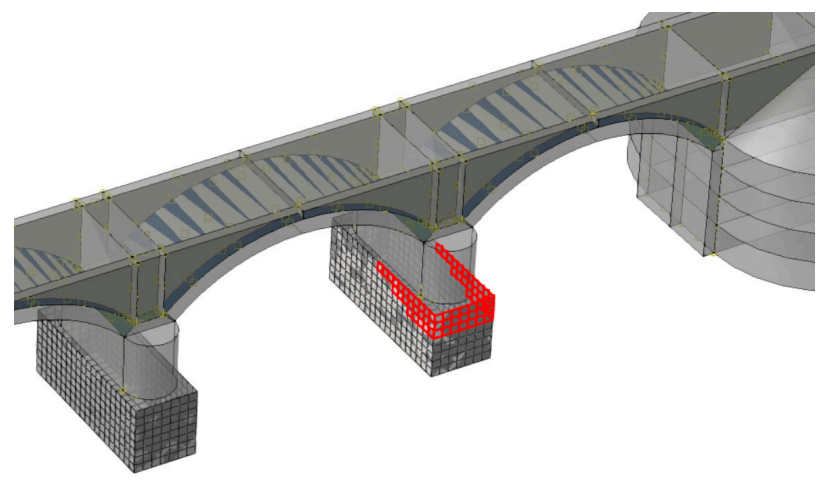

(a)

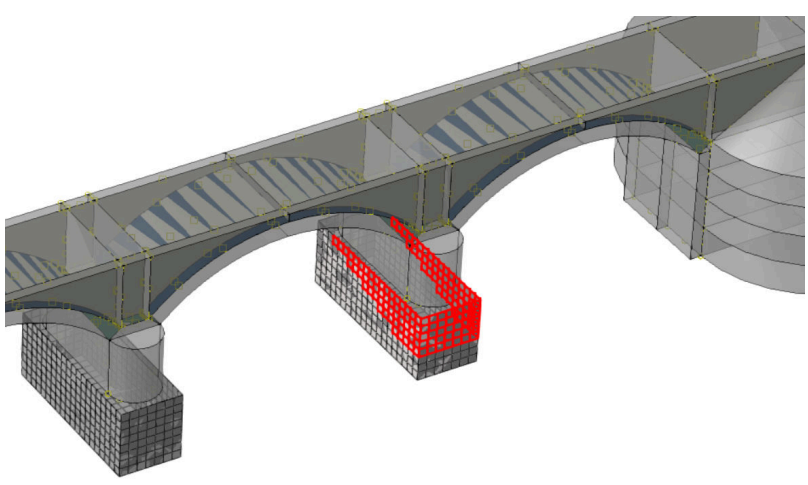

(b) 


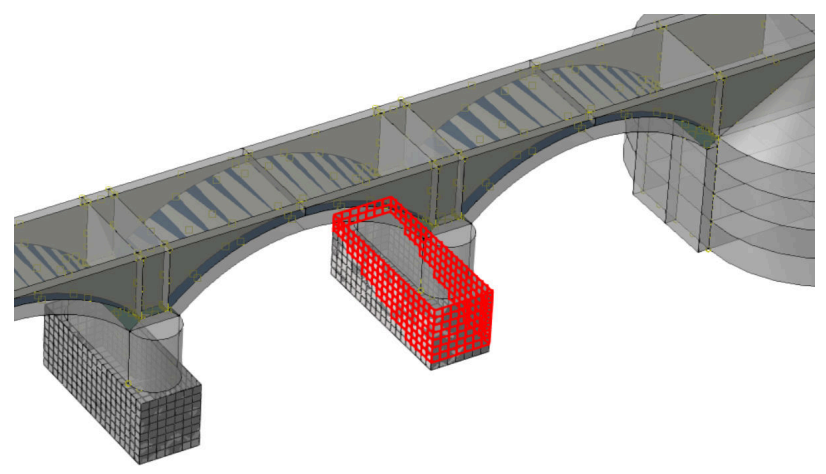

(c)

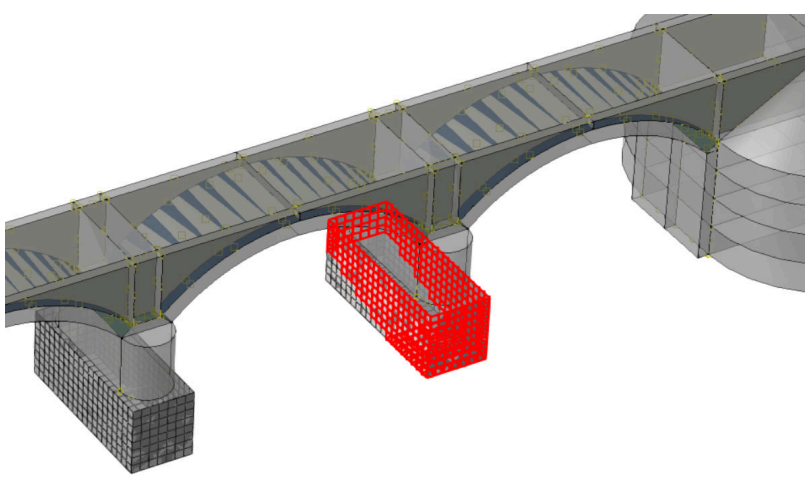

(d)

Figure 10. Scour simulation by progressively deactivating pier's impedance elements.

From the numerical point of view, the simulation described above is performed via a series of alternate nonlinear static analyses and frequency (eigenvalues) analyses. More precisely, each Step (from 0 to 7 ) consists of:

1) a nonlinear static analysis, with direct equation solver based on the Full-Newton solution technique available in ABAQUS/Standard, in which gravity loads are applied (Step 0) and the scour is gradually simulated (Steps 1 to 7$)$;

2) a linear perturbation frequency analysis, using the Lanczos eigen-solver, which includes the effects due to the previous nonlinear static analysis (i.e., the changes in stiffness and boundary conditions due to the scour process evolution). By this way, both the natural frequencies and the corresponding modal shapes can be extracted at the end of each nonlinear static analysis simulating the scour evolution.

\subsection{Operational modal analysis}

An experimental campaign was carried out in March 2018 to characterize the dynamic response of the remaining part of the bridge. OMA $[15,16]$ is performed by measuring vibrations produced by the ambient excitation, under the assumption that this noise can be described as a zero mean Gaussian stochastic process (white noise) characterized by a broadband spectrum, able therefore to excite all the system's frequencies. Due to its ease of implementation, OMA has become particularly attractive 
in the last decades also for identifying civil engineering structures (e.g., buildings, bridges), as demonstrated by some relevant recent applications [21-24].

For what concerns the present study, the experimental setup (i.e., equipment and sensor configurations) is discussed in Section 3.2.1 whereas the results of OMA are presented in Section 3.2.2.

\subsubsection{Experimental setup}

The experimental test equipment consists of:

- 10 monoaxial piezoelectric accelerometers (PCB manufacturer, 393B31 series).

- Shielded coaxial cables.

- 1 (eight-slot) USB chassis NI cDAQ 9178 equipped with 3 NI 9234 4-channel dynamic signal acquisition modules (24-bit).

- Laptop for data acquisition with dedicated software.

Four different experimental setups were adopted, by modifying the accelerometers position and orientation along both transversal and longitudinal directions:

- $\quad$ Setup 1: 2AY, 2AZ, 2BZ, 1AY, 1AZ, 1BZ, 3AY, 3AZ, 3BZ, 0AY;

- Setup 2: 2AY, 2AZ, 2BZ, 5AZ, 4AZ, 4BZ, 5BZ, 6AZ, 6BZ, 0AZ;

- $\quad$ Setup 3: 2AY, 2AZ, 2BZ, 5AY, 4AY, 1AZ, 5BX, 6AY, 3AZ, 0AZ.

- $\quad$ Setup 4: 2AY, 2AZ, 2BZ, 1AX, 4AY, 0BZ, 1BX, 3AX, 3BX, 0AZ.

where each sensor is identified based on position and orientation (see Figure 11). For what concerns the longitudinal placement, the sensors positioned in correspondence of the piers are identified by numbers from 1 to 3 (ascending from the abutment), whilst sensors at middle span locations with numbers from 4 to 6 . The sensors located in correspondence of the abutment are identified by the number 0 . The labels A or B denote the transversal placement along the bridge deck. Finally, suffix $\mathrm{X}, \mathrm{Y}$ or $\mathrm{Z}$ identify the sensor orientation, according to the reference system of Figure 11 . Sensors 2AY, $2 \mathrm{AZ}$ and 2BZ were kept fixed in their position throughout the whole experimental campaign to 
allow the merging operation of data from each setup into one single model of the structural system. For this purpose, a post-identification method was used, usually referred to as Post Separate Estimation Re-scaling (PoSER) approach [25]. This approach consists of averaging the natural frequencies resulting from all setups and merging the obtained (partial) mode shapes by re-scaling them to compensate the effects of potential different excitation factors characterizing the various test configurations.

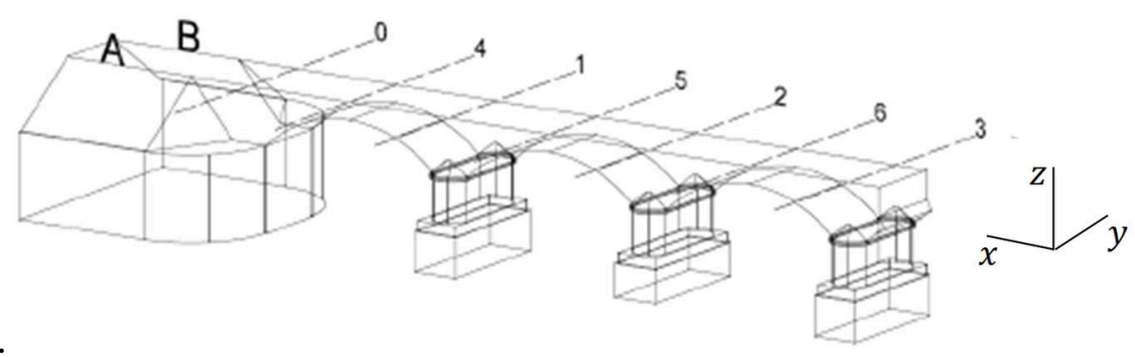

Figure 11. Scheme of sensor location.

Once acquired, the signals were processed via standard signal processing techniques aimed to: eliminate anomalous average trends through a baseline correction with a $3^{\text {th }}$ degree polynomial fitting procedure; eliminate high frequency contributions and thus avoid aliasing by digitally filtering the signal trough a 4th-order lowpass Butterworth filter with a cut-off frequency of $25 \mathrm{~Hz}$ and a resampling frequency of $51.2 \mathrm{~Hz}$; reduce data size and consequently boost analysis by resampling the signals at a lower frequency rate. Modal identification was performed by using the Covariance-based Stochastic Subspace Identification (SSI-Cov) method [26,27], commonly employed for ambient vibration analysis on bridge structures [21,28]. Measurements were registered with a sampling rate of $2048 \mathrm{~Hz}$.

During the tests, the values of air temperature and relative humidity, monitored with standard sensors, remained almost constant. Moreover, the wind velocity was quite low and constant during tests. Environmental parameters, especially wind velocity and environmental temperature, are known to affect the modal parameters of structures (see [29] for a general overview on the topic, and the more specific works by [30-32]), however, in this case, in view of the low changes of environmental 
conditions, the modal parameters of the bridge are assumed to be constant during the ambient measurements.

\subsubsection{Numerical vs experimental modal results}

Table 4 reports and compares the frequencies of the first three modes of vibration obtained via OMA and by using the numerical model of the three-span bridge developed in Abaqus [17], with the elastic properties summarised in Table 1. It can be observed that the numerical results are in good agreement with the OMA results. The maximum normalized deviation between measured and numerical frequencies is less than $5 \%$. The match in terms of mode shapes is also satisfactory, as it can be seen in Figure 12. Specifically, a 3D view of the numerical mode shapes is provided in Figure 12a, while a comparison between numerical (blue lines) and experimental (red lines) mode shapes is given in Figure $12 \mathrm{~b}$ by using a plan view from the top.

The MAC values [33] between numerical and experimental modes are provided in Table 5.
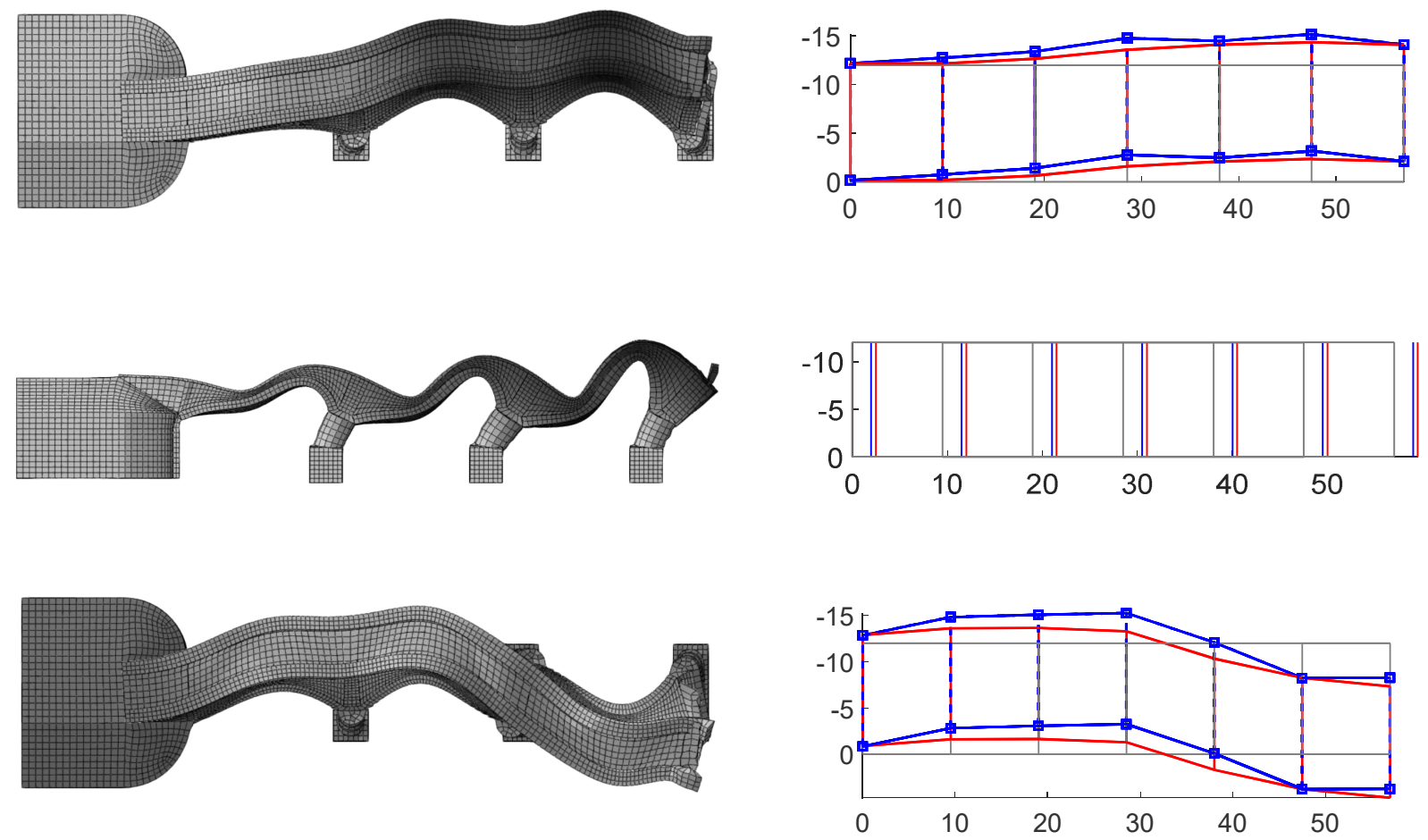

(a)

(b)

Figure 12. (a) 3D view of numerical mode shapes and (b) comparison between numerical (blue) and experimental (red) mode shapes. 
Table 4. FEM vs OMA modal frequencies

\begin{tabular}{cccc}
\hline $\begin{array}{c}\text { Mode } \\
{[-]}\end{array}$ & \multicolumn{2}{c}{$\begin{array}{c}\text { Frequency } \\
{[\mathrm{Hz}]}\end{array}$} & $\begin{array}{c}\text { Error } \\
{[\%]}\end{array}$ \\
\hline & FEM & OMA & \\
\hline 1 (transversal) & 6.16 & 5.90 & -4.41 \\
\hline 2 (longitudinal) & 5.94 & 5.95 & 0.17 \\
\hline 3 (transversal) & 6.51 & 6.80 & 4.26 \\
\hline
\end{tabular}

Table 5. MAC matrix between numerical and experimental modes of vibration.

\begin{tabular}{c|ccc}
\hline & Long. & Transv. 1 & Transv. 2 \\
\hline Long. & $\mathbf{0 . 9 9}$ & 0.00 & 0.00 \\
\hline Transv. 1 & 0.00 & $\mathbf{0 . 9 5}$ & 0.08 \\
\hline Transv. 2 & 0.00 & 0.24 & $\mathbf{0 . 8 0}$ \\
\hline
\end{tabular}

\section{SCOUR-INDUCED COLLAPSE SIMULATION}

This section illustrates the effects of the scour progression at the base of pier $n$. 6 of the original bridge (the scouring action is assumed to be localized only in correspondence of this pier). As already described before, the simulation of the deepening of the scour hole is achieved by considering 8 analysis Steps: Step 0 accounts for the starting condition, with no scour taking place and gravity loads acting on the bridge; from Step 1 to Step 7 the scour development under the pier n. 6 is simulated by considering increments of $y_{s}$ equal to $1.0 \mathrm{~m}$ per step, for a total maximum scour depth of $7.0 \mathrm{~m}$ attained at Step 7, corresponding to a maximum excavation of $3.0 \mathrm{~m}$ under the up-stream side of the pier's foundation (whose height is $4.15 \mathrm{~m}$, as discussed in section 2.1). It is noteworthy that the maximum value of the scour depth attained in the simulation is $y_{s}=6.5 \mathrm{~m}$, beyond which convergence issues occur. Thus, the complete excavation of the soil surrounding the pier cannot be fully simulated.

Figure 13 shows the evolution of the Von Mises stresses (colours from blue to red identifies the transition from compression to tension states) at different stages of scour development. An almost symmetric stress distribution is observed (Figure 13a) on all spans and piers up to scour depths lower 
than the foundation depth $(4.15 \mathrm{~m})$. High tensile stress values, with peaks around $150 \mathrm{kN} / \mathrm{m}^{2}$, are observed in the spandrel walls above the piers. At the end of Step 5, i.e., when $y_{s}$ attains the value of $5.0 \mathrm{~m}$, stresses start concentrating on the pier 6, which also begins rotating (as shown in Figure 13b, with displacements amplified by scale factor 100). Finally, for $y_{s}>5.0 \mathrm{~m}$, the stress concentration on the arches and spandrels adjacent to pier $n .6$ becomes very significant, together with the rocking effect (as shown in Figure 13c, with displacements amplified by a scale factor of 60).

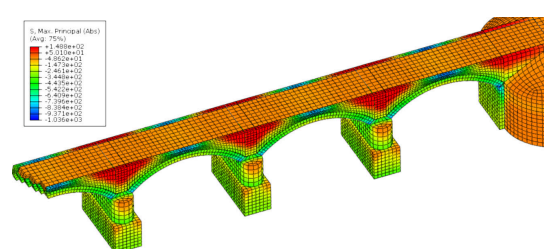

(a)

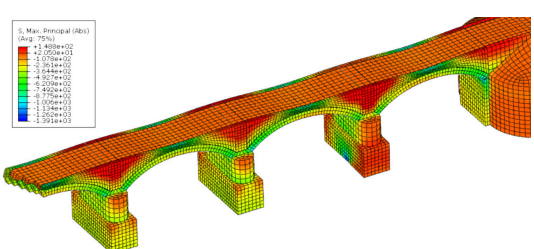

(b)

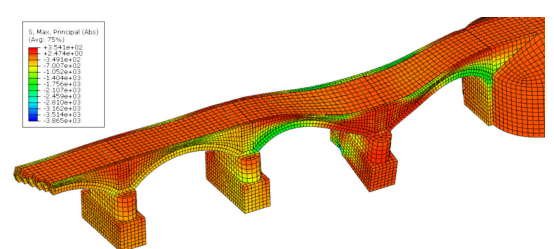

(c)

Figure 13. Von Mises stresses evolution at different stages of scour development: (a) $y_{s}<4.0 \mathrm{~m}$; (b) $y_{s}=5.0 \mathrm{~m}$; (c) $y_{s}>5.0 \mathrm{~m}$. Colours from blue to red correspond to stress values from $-1000 \mathrm{kN} / \mathrm{m}^{2}$ (compression) to $+150 \mathrm{kN} / \mathrm{m}^{2}$ (tension).

Figure 14 illustrates the relation between the pier's vertical settlement $u_{z}$ (measured under the upstream side of the foundation) and the scour depth $y_{s}$. It is observed how the effects of scour are negligible for depths of scour less than the foundation depth of $4.15 \mathrm{~m}$ (Steps 0-4). The vertical settlement notably increases for higher depths of scour such that the soil below the foundation is undermined. According to Figure 14, the value $y_{s}=5.5 \mathrm{~m}$ identifies the limit beyond which small increments of the scour depth induce very high damage on the structure, and therefore this value can be assumed as the maximum scour depth at incipient collapse.

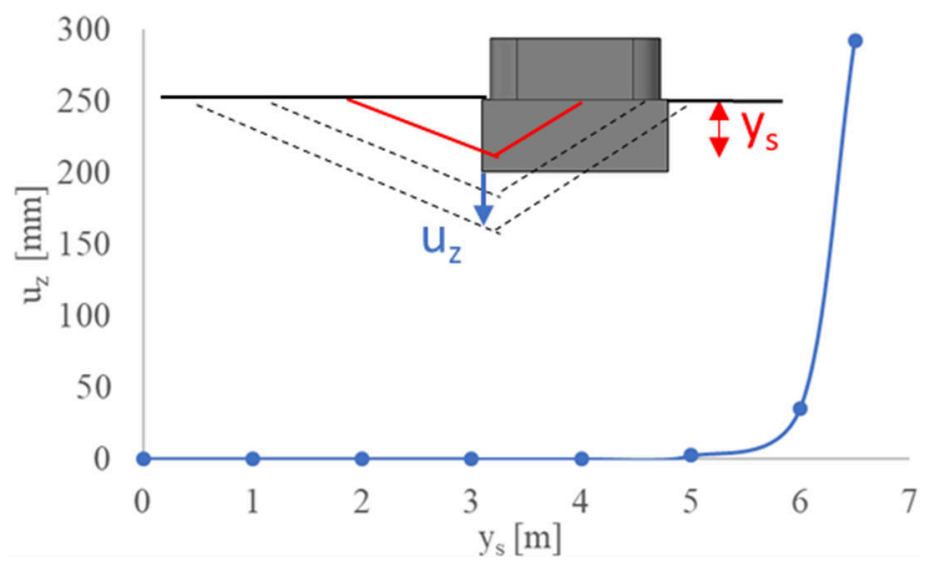

Figure 14. Plot of $u_{z}-y_{s}$ response for pier n. 6 . 
Figure 15 shows the Von-Mises plastic strain $\left(\varepsilon_{p l}\right)$ distribution on the bridge before the end of Step 6, i.e., for $y_{s}$ between 5 and $6 \mathrm{~m}$. In the figure, the blue and green colour correspond to $\varepsilon_{p l}$ values of the order of $10^{-4}$ to $10^{-3}$. This result suggests that the failure occurs at the two sides of the spans, in correspondence of the connection with the abutment on the one side and with the pier on the other side.

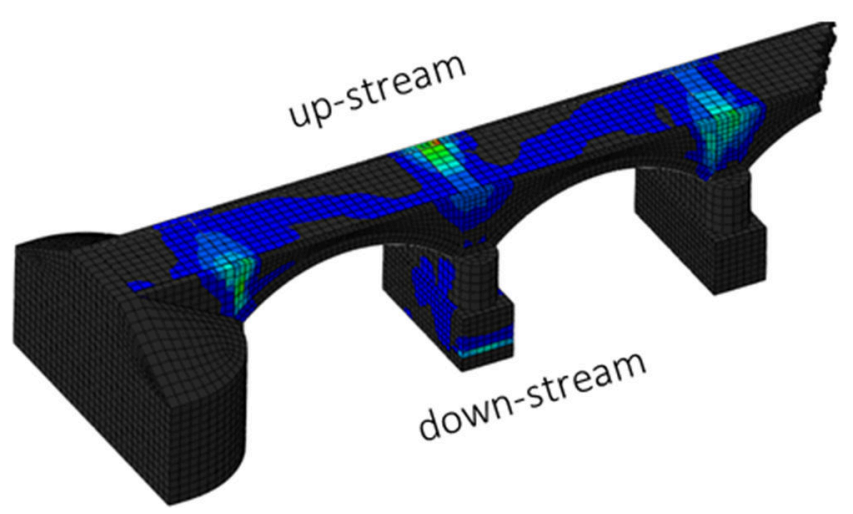

Figure 15. Plastic strain distribution for $y_{s}$ between 5.0 and $6.0 \mathrm{~m}$. Colours from blue to green correspond to $\varepsilon_{p l}$ values from $10^{-4}$ to $10^{-3}$.

For sake of completeness, the plastic strain $\varepsilon_{p l}$ developed on the spandrel wall at the location with maximum tensional demand (i.e., above the pier on the down-stream side, as highlighted in Figure 16 by a red circle) is plotted in Figure 16 as a function of the scour depth $y_{s .}$. The concentration of stresses with values comparable to the masonry tensile strength $\left(150 \mathrm{kN} / \mathrm{m}^{2}\right)$ leads to some very small values of $\varepsilon_{p l}$ (lower than $10^{-5}$ ) identified before the scour initiation (i.e., for $y_{s}=0.0 \mathrm{~m}$ ). These $\varepsilon_{p l}$ values remain constant until the scour depth is lower than $4.15 \mathrm{~m}$, then a sudden rise in plastic strains is observed for small increments of the scour, according to a trend very similar with the one noted before (Figure 15) for the pier's vertical settlement $u_{z}$. 


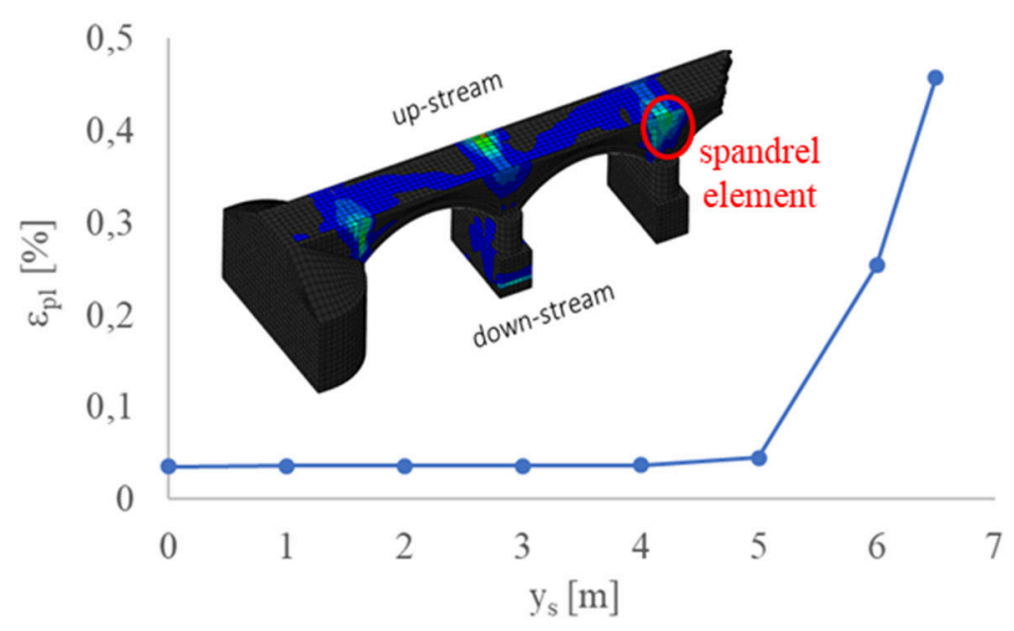

Figure 16. Spandrel plastic strain (down-stream side, above Pier) as a function of the scour depth. For what concerns the arches, it can be observed (Figure 17) that the scour depth $y_{s}=5.50 \mathrm{~m}$ induces the formation of diagonal cracks located in proximity of the pier n. 6 . It is worth noting how both the shape and location of such cracks under the arch barrels are similar to those observed in the work [3], concerning a different masonry arch bridge.

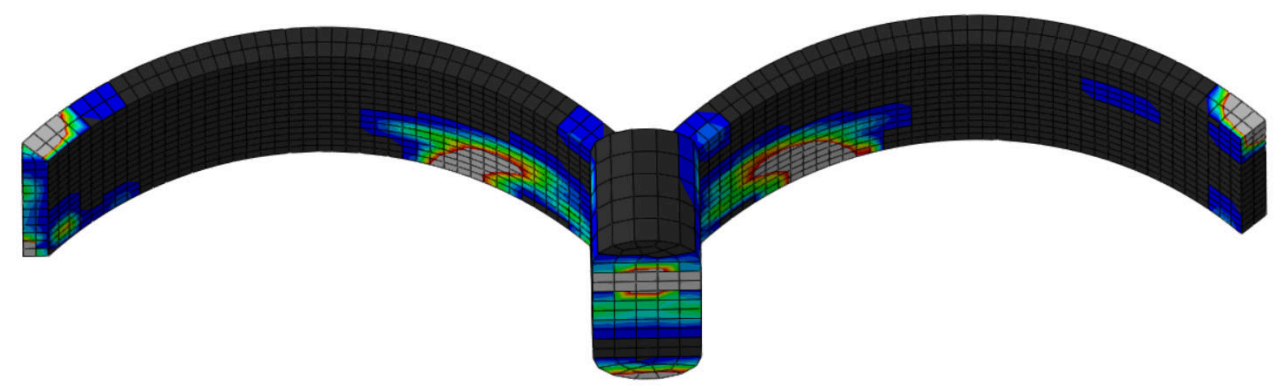

Figure 17. Onset of diagonal crack (plastic strain plot) under the arch barrels for $y_{s}=5.50 \mathrm{~m}$ (downstream view). Colours from blue to red correspond to $\varepsilon_{p l}$ from $10^{-4}$ to $10^{-2}$; grey colour identifies $\varepsilon_{p l}>10^{-2}$.

For values of $y_{s}$ higher than $5.50 \mathrm{~m}$, the damage propagation is very fast and the extent of plastic deformations is significant. For instance, Figure 18 a shows the diffusion of plastic strains inside the bridge (involving backfill, spandrel walls and arches) for $y_{s}=6.00 \mathrm{~m}$ (Figure 18a) and $y_{s}=6.50 \mathrm{~m}$ (Figure 18b). 


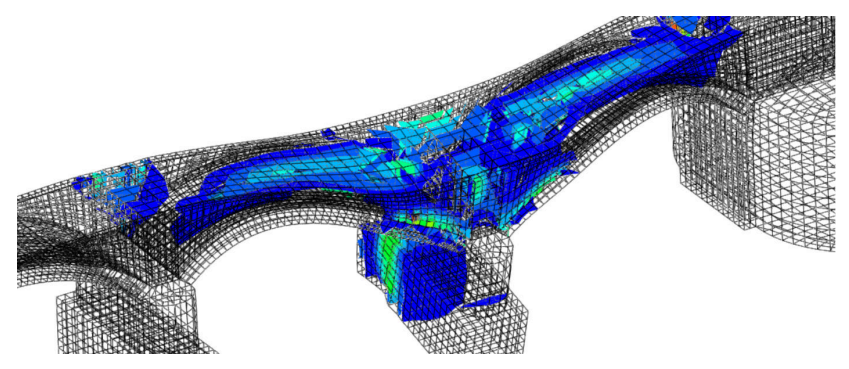

(a)

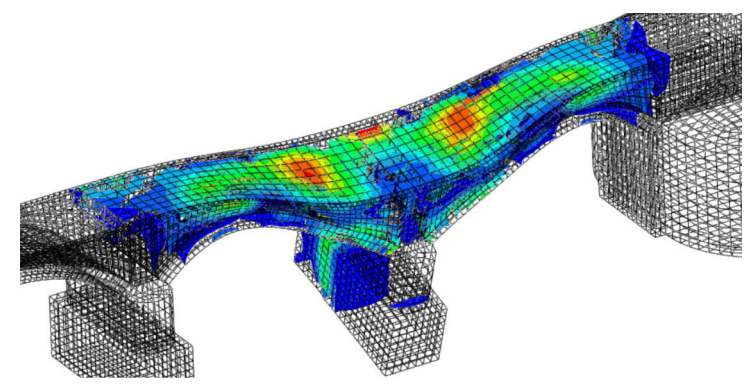

(b)

Figure 18. Plastic strain distribution inside the bridge for: (a) $y_{s}=6.00 \mathrm{~m}$ and (b) $y_{s}=6.50 \mathrm{~m}$. Colours from blue to red correspond to $\varepsilon_{p l}$ values from $10^{-4}$ to $10^{-1}$.

Based on the results shown in this section, it is possible to conclude that the partial collapse of Rubbianello bridge was caused by the attainment of a scour level of around $5.50 \mathrm{~m}$ after the intense flood on 2013. Moreover, the failure pattern and the location of the cracks identified within this simulation, as well as the rotational mechanism induced by the scour at the base of the pier, are in line with the post-collapse state of the bridge observed after the 2013 flood (see Figure 1).

Finally, a remark is due about the effect of the linear model adopted for the soil in compression. In this regard, it shall be noted that the stress levels monitored during the numerical analyses in the soil underneath the foundations do not exceed 0.4 MPa, while the limit strength for the soil (highly dense gravel and sands) is higher than $0.6 \mathrm{MPa}$, according to geotechnical analysis results. Only at the final stages of the analyses, just before the attainment of the maximum simulated scour depth of ys $=6.5$ m (beyond which convergence issues occur), significant increments of the soil stresses are observed under the pier n.6. In light of this, and being the main goal of the analysis the prediction of the scour depth at the onset of the failure conditions (i.e., for $y s=5.50 \mathrm{~m}$ ), the assumption of a linear behaviour of the soil in compression should not introduce significant errors that compromise the results. A more accurate modelling strategy for the soil might be required for simulating the full collapse mechanism of the bridge-soil system, but this is out of the scope of the work. 


\section{SCOUR INFLUENCE ON BRIDGE'S DYNAMIC PROPERTIES}

This last section aims to assess the effects of the scour on the modal properties the bridge. Figure 19 (at the top) shows the shape of the transversal vibration mode (when no scour is in place), which is the one most sensible to the effects of scour. The frequency of vibration corresponding to this mode, whit no scour taking place, is $6.453 \mathrm{~Hz}$.

Table 6 illustrates the evolution of the frequency of this mode with the scour depth progression. The changes of the modal frequency are very low for increasing scour depths between $0.0 \mathrm{~m}$ and $4.0 \mathrm{~m}$, with a percentage decrease of $1.5 \%$ at Step 4 (i.e., with $y_{s}=4.0 \mathrm{~m}$ ). From this point on, the effects of the scour on the modal frequency become more and more significant: a percentage reduction of $21 \%$ is observed at Step 5 (i.e., with $y_{s}=5.0 \mathrm{~m}$, meaning $1.0 \mathrm{~m}$ of excavation under the pier), while a reduction of $47 \%$ is observed at Step 6 (i.e., with $y_{s}=6.0 \mathrm{~m}$, meaning $2.0 \mathrm{~m}$ of excavation under the pier). Thus, the frequency changes remain negligible until the scour depth involves only the lateral sides of the foundation, without affecting the soil underneath.

Table 6. Frequency evolution $(\mathrm{Hz})$ due to scour depth progression

\begin{tabular}{ccccccc}
\hline Step 0 & Step 1 & Step 2 & Step 3 & Step 4 & Step 5 & Step 6 \\
$0.0 \mathrm{~m}$ & $1.0 \mathrm{~m}$ & $2.0 \mathrm{~m}$ & $3.0 \mathrm{~m}$ & $4.0 \mathrm{~m}$ & $5.0 \mathrm{~m}$ & $6.0 \mathrm{~m}$ \\
\hline 6.455 & 6.453 & 6.445 & 6.428 & 6.357 & 5.077 & 3.431 \\
\hline
\end{tabular}

Figure 19 illustrates the evolution of the transverse mode shape obtained for the different stages of scour progression. The mode shape is found to be more sensitive to the effect of scour compared to the frequency of vibration. Interestingly, a non-negligible variability of the transverse mode shape is observed starting from the early stages of the scour phenomenon, i.e., for $y_{s}$ between 1.5 and $2.0 \mathrm{~m}$, which is before the scour depth becomes higher than the foundation height (hence no excavation under the pier's foundation is undergoing). As the scour proceeds, the displacements of the transverse mode tend to increase in correspondence of the subsiding pier (n. 6) compared to the rest of the bridge. They are highly localized at this pier for $y_{s}>4.0 \mathrm{~m}$, i.e., when the scour depths becomes higher than the foundation height $(4.15 \mathrm{~m})$. 
According to the outcomes provided by this last simulation, it can be concluded that a scour monitoring technique based on the modal frequencies identification would not be possible on this specific case study, in particular if the aim is to use it as an early warning system. The changes in frequency, indeed, become noticeable (higher than 20\%) only at the more advanced stages of the scour progression. For this reason, and by also considering the potential variability of the frequencies measured via OMA, due to both environmental factors (i.e., temperature, wind, etc.) and noise in the signals (particularly high for these types of structural systems mainly because of the high rigidity and the heterogeneity of the component materials) the suitability of a frequency-oriented identification system based on ambient vibrations might be very compromised. On the other hand, a mode shapeoriented identification system could be more appropriate, in light of the observed mode shapes sensitivity to the investigated phenomenon since the early stages of the scour progression.

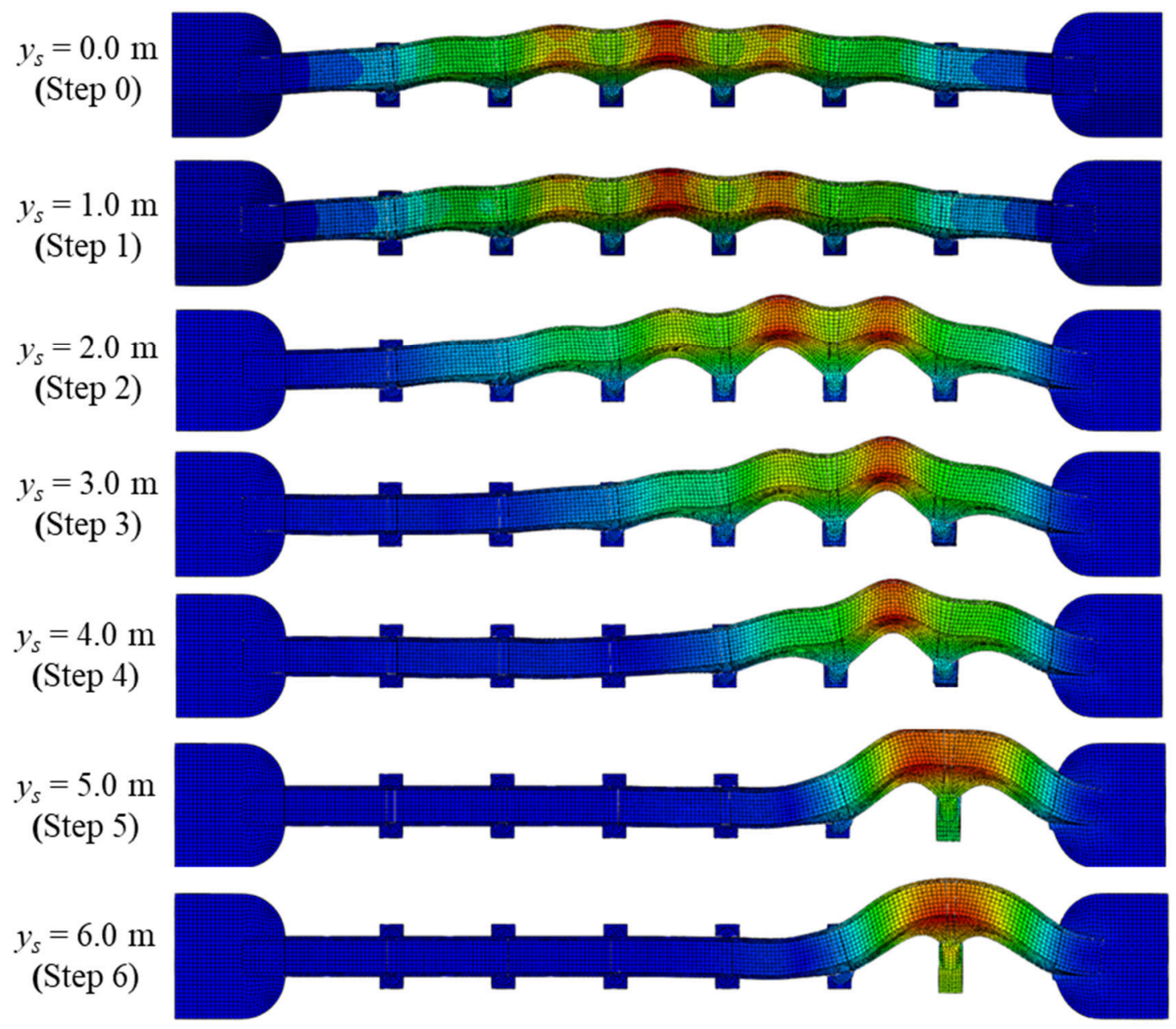

Figure 19. Transverse mode shapes variation for different scour depths. 


\section{CONCLUSIONS}

The problem of the flood-induced scour on masonry arch bridge is investigated. A specific case study is considered: the Rubbianello Bridge, a multi-span masonry arch bridge located in Central Italy, which suffered the collapse of two of the seven spans due to foundation scour during a very severe flood in December 2013. The study on one hand aims to simulate numerically the collapse mechanism and characterise the level of scour which led the bridge to failure in 2013; on the other hand, it has the objective to evaluate the sensitivity of the bridge modal properties (vibration frequencies and mode shapes) to scour progression, in order to assess whether Operational Modal Analysis (OMA) can be used for scour detection. An accurate nonlinear 3D model of the bridge is developed, in which the elastic properties are calibrated via OMA-based dynamic identification tests performed on the remaining part of the bridge. A numerical simulation of the scour hole progression is performed according to recently proposed techniques, by adopting a simplified Winkler approach for the soilfoundation interaction.

Based on the outcomes of this study, the following conclusions can be drawn.

For what concerns the collapse assessment:

- The entity of the scour depth which produced the collapse of Rubbianello bridge in 2013 is approximatively equal to $5.5 \mathrm{~m}$, corresponding to an excavation of the order of $1.50 \mathrm{~m}$ under the foundation base of the pier.

- The proposed model is capable to simulate the actual collapse mechanism of the bridge, characterized by a rotation of the pier towards the upstream side and by the failure of the masonry components (both arches and spandrels) adjacent to pier n. 6 due to exceedance of tensile capacity.

- The proposed modelling approach allows performing a bridge scour assessment without significant computational effort. Thus, it is suitable for extensive parametric studies aimed at evaluating the vulnerability of masonry arch bridges to scour.

For what concerns the modal properties' sensitivity: 
- The modal frequency changes are negligible if the scour depth involves only the lateral sides of the foundation.

- The changes in frequency becomes noticeable (higher than $20 \%$ ) only at the more advanced stages of the scour progression, i.e., when the soil underneath the pier is eroded. For this reason, and given the potential variability of the frequencies measured via OMA (environmental factors, noise in the signals), the suitability of a frequency-oriented identification system based on ambient vibrations might be compromised.

- The transverse mode shape exhibits a very high sensitivity to scour, since the early stages of the phenomenon, i.e., for scour depths lower than the foundation height such that the erosion affects only the soil above the foundation level.

In light of the above, a mode shape-oriented identification system might be appropriate for monitoring the scour evolution over the time and thus intervene timely in order to avoid failure or damage development on masonry bridges. However, it should be noted that this result has a general validity for cases in which the scour is concentrated on a limited number of piers, for instance because of the meandering feature of the river (as in this case), whereas the study shall be extended to a wider set of case studies in order to verify the effectiveness of the proposed OMA-based identification technique as a scour monitoring and early warning strategy in those cases in which scour affects a larger number of piers.

Moreover, as further development, the problem of the influence of scour on the seismic vulnerability of masonry arch bridges will be addressed.

\section{REFERENCES}

[1] Hoffmans GJCM, Verheij HJ. Scour Manual. Routledge; 2017. doi:10.1201/9780203740132.

[2] Melville BW, Coleman SE. Bridge scour. Water Resources Publications, LLC; 2000.

[3] Tubaldi E, Macorini L, Izzuddin BA. Three-dimensional mesoscale modelling of multi-span masonry arch bridges subjected to scour. Engineering Structures 2018;165:486-500. 
doi:10.1016/J.ENGSTRUCT.2018.03.031.

[4] Sousa JJ, Bastos L. Multi-temporal SAR interferometry reveals acceleration of bridge sinking before collapse. Natural Hazards and Earth System Sciences 2013;13:659-67. doi:10.5194/nhess-13-659-2013.

[5] Gavin K, Obrien EJ. Sustainable Maintenance and Analysis of Rail Transport Infrastructure (SMART rail) Railway bridge safety and condition assessment View project Smart Rail View project. 2012.

[6] Maddison B. Scour failure of bridges. Proceedings of the Institution of Civil Engineers Forensic Engineering 2012;165:39-52. doi:10.1680/feng.2012.165.1.39.

[7] Page J. Masonry arch bridges. TRL-State of the art review, Department of Transport 1993.

[8] Zampieri P, Zanini MA, Faleschini F, Hofer L, Pellegrino C. Failure analysis of masonry arch bridges subject to local pier scour. Engineering Failure Analysis 2017;79:371-84. doi:10.1016/J.ENGFAILANAL.2017.05.028.

[9] Zhang Y, Tubaldi E, Macorini L, Izzuddin BA. Mesoscale partitioned modelling of masonry bridges allowing for arch-backfill interaction. Construction and Building Materials 2018;173:820-42. doi:10.1016/J.CONBUILDMAT.2018.03.272.

[10] Milani G, Lourenço PB. 3D non-linear behavior of masonry arch bridges. Computers \& Structures 2012;110-111:133-50. doi:10.1016/J.COMPSTRUC.2012.07.008.

[11] Ruocci G. Application of the SHM methodologies to the protection of masonry arch bridges from scour. PhD Thesis, Polytechnic University of Torino, 2010.

[12] Foti S, Sabia D. Influence of Foundation Scour on the Dynamic Response of an Existing Bridge. Journal of Bridge Engineering 2011;16:295-304. doi:10.1061/(ASCE)BE.19435592.0000146.

[13] Ju SH. Determination of scoured bridge natural frequencies with soil-structure interaction. Soil Dynamics and Earthquake Engineering 2013;55:247-54. doi:10.1016/J.SOILDYN.2013.09.015. 
[14] Prendergast LJ, Hester D, Gavin K, O’Sullivan JJ. An investigation of the changes in the natural frequency of a pile affected by scour. Journal of Sound and Vibration 2013;332:6685702. doi:10.1016/J.JSV.2013.08.020.

[15] Rainieri C, Fabbrocino G. Operational Modal Analysis of Civil Engineering Structures. 2014. doi:10.1007/978-1-4939-0767-0.

[16] Brincker R, Ventura CE. Introduction to Operational Modal Analysis. 2015. doi:10.1002/9781118535141.

[17] Abaqus, V. (2014). 6.14 Documentation. Dassault Systemes Simulia Corporation, 651. 2014.

[18] Carbonari S, Morici M, Dezi F, Leoni G. A lumped parameter model for time-domain inertial soil-structure interaction analysis of structures on pile foundations. Earthquake Engineering \& Structural Dynamics 2018;47:2147-71. doi:10.1002/eqe.3060.

[19] Gazetas G. Formulas and Charts for Impedances of Surface and Embedded Foundations. Journal of Geotechnical Engineering 1991;117:1363-81. doi:10.1061/(ASCE)07339410(1991)117:9(1363).

[20] Tubaldi E, Macorini L, Izzuddin BA, Manes C, Laio F. A framework for probabilistic assessment of clear-water scour around bridge piers. Structural Safety 2017;69:11-22. doi:10.1016/J.STRUSAFE.2017.07.001.

[21] Gara F, Roia D, Speranza E. Dynamic structural control of the "Caffaro Viaduct" by means of vibrational measurements. 2016 IEEE Workshop on Environmental, Energy, and Structural Monitoring Systems (EESMS), IEEE; 2016, p. 1-6. doi:10.1109/EESMS.2016.7504824.

[22] Ivorra S, Foti D, Bru D, Baeza FJ. Dynamic Behavior of a Pedestrian Bridge in Alicante, Spain. Journal of Performance of Constructed Facilities 2013. doi:10.1061/(asce)cf.19435509.0000556.

[23] Diaferio M, Foti D, Gentile C, Giannoccaro NI, Saisi A. Dynamic testing of a historical slender building using accelerometers and radar. 6th International Operational Modal Analysis Conference, IOMAC 2015, 2015. 
[24] Ivorra S, Foti D, Paparella F, Baeza FJ. Dynamic load tests on the North-South axis cablestayed bridge with a non-symmetric central pylon. Procedia Engineering, 2017. doi:10.1016/j.proeng.2017.09.528.

[25] Reynders, Edwin and Magalhaes, Filipe and Roeck, GD and Cunha A. Merging Strategies for Multi-Setup Operational Modal Analysis: Application to the Luiz I steel Arch Bridge. Proceedings of IMAC 27, the International Modal Analysis Conference 2009.

[26] Peeters B, De Roeck G. Reference-Based Stochastic Subspace Identification For Output-Only Modal Analysis. Mechanical Systems and Signal Processing 1999;13:855-78. doi:10.1006/MSSP.1999.1249.

[27] Peeters B, De Roeck G. Stochastic system identification for operational modal analysis: a review. Journal of Dynamic Systems, Measurement, and Control 2001;123:659-67.

[28] Ubertini F, Gentile C, Materazzi AL. Automated modal identification in operational conditions and its application to bridges. Engineering Structures 2013;46:264-78. doi:10.1016/J.ENGSTRUCT.2012.07.031.

[29] Sohn H. Effects of environmental and operational variability on structural health monitoring. Philosophical Transactions of the Royal Society A: Mathematical, Physical and Engineering Sciences 2007. doi:10.1098/rsta.2006.1935.

[30] Azzara RM, De Roeck G, Girardi M, Padovani C, Pellegrini D, Reynders E. The influence of environmental parameters on the dynamic behaviour of the San Frediano bell tower in Lucca. Engineering Structures 2018. doi:10.1016/j.engstruct.2017.10.045.

[31] Gentile C, Guidobaldi M, Saisi A. One-year dynamic monitoring of a historic tower: damage detection under changing environment. Meccanica 2016. doi:10.1007/s11012-016-0482-3.

[32] Regni M, Arezzo D, Carbonari S, Gara F, Zonta D. Effect of Environmental Conditions on the Modal Response of a 10-Story Reinforced Concrete Tower. Shock and Vibration 2018;2018:1-16. doi:10.1155/2018/9476146.

[33] Pastor M, Binda M, Harčarik T. Modal Assurance Criterion. Procedia Engineering 
2012;48:543-8. doi:10.1016/J.PROENG.2012.09.551. 